\title{
Accessing with Dinosaurs: Protecting Access to Government Information in the Cretaceous Period of Canadian Democracy
}

\section{Vincent Kazmierski*}

The fossil remains of Triceratops date to the very end of the Cretaceous period, only slightly before the meteor impact that killed the dinosaurs. By this time, paleontologists believe, dinosaur evolution had slowed to a crawl and the resulting loss of diversity virtually guaranteed their quick extinction. Along with its fellow herbivores, Triceratops was doomed by the loss of its accustomed vegetation, as clouds of dust circled the globe in the wake of the K/T explosion. ${ }^{1}$

In many ways, our democratic institutions, processes, and frameworks resemble the dinosaurs of the Cretaceous period described above. They have ceased to evolve sufficiently and are being left behind in an environment where technological innovations and greater expectations for political consultation, participation, and accountability have combined to present new challenges to the legitimacy, and perhaps the viability, of the status quo. Indeed, without further evolution, one wonders how our democratic dinosaurs will be able to survive cataclysmic events on the horizon, including escalating terrorism events and their aftermath.

This paper will explore the fate of one such democratic dinosaur, the federal Access to Information Act. ${ }^{2}$ The Access Act is the primary tool that protects our right to access federal government information. This right is widely recognized as important to ensure government accountability and to promote political partici- pation by citizens. Notwithstanding the importance of protecting this right, the Access Act has not been updated in any meaningful way since it was first enacted in 1982, despite widespread recognition of the need for modernization. While the legislative framework has remained static, new and greater threats to our right to access government information have developed. These threats include bureaucratic delays and refusals, political interference with access requests, failure to keep adequate records, and new legislative provisions designed to reduce access or even eliminate access investigations retroactively.

As a result, the Access Act stands as the Triceratops in the Cretaceous period, clad with some protections against predators who would restrict our rights to access government information, but ultimately ill-prepared to face the threats of increasingly effective predators and certainly unprepared to deal with the changing environment or to adjust to cataclysmic events. In light of this, I will consider three ways that the right to access government information, along with other democratic rights, should evolve to more effectively face its predators, to better adapt to the changing environment, and to ensure its protection when faced with cataclysmic events. These evolutionary imperatives include legislative renewal, executive action, and judicial protection of access to government information. 
Recognizing the dire need to modernize the legislative framework for access to government information, I will argue for two key amendments to the Access Act that will enhance protection of the right to access government information: providing the Federal Commissioner with ordermaking power, and imposing a positive duty to document decisions. I will also argue for a shift in the orientation of the Executive to the Access Act. This shift must take root within the Canadian Civil Service and be championed by political leaders, including the Prime Minister and the rest of the Cabinet. The shift in orientation would facilitate further administrative steps to increase access to information, including providing sufficient resources to process access requests in a timely manner and changing administrative guidelines to minimize mechanisms for evading access requests. Finally, I will argue for three key roles for the Canadian courts in enforcing the right to access government information. These roles include fortifying the constitutional protection of access to government information, reinforcing a purposive approach to interpreting the scope of legislative rights to access information, and continuing to require robust justifications for the exercise of administrative discretion to refuse to disclose government information.

\section{A. Legislative Evolution: Modernizing the Access to Information Act}

For over a decade, successive Information Commissioners have recognized the need to modernize the Access Act, each presenting extensive proposals for improvement. ${ }^{3}$ Commissioner Legault's 2015 special report entitled Striking the Right Balance for Transparency, is the most recent proposal for a comprehensive reform; the Commissioner advanced 85 recommendations for fundamental changes to the federal Access Act. ${ }^{4}$ While I agree with the vast majority of the reforms recommended by the Commissioner, it is beyond the scope of this paper to consider these recommendations in detail. However, I will endorse two of the major recommendations made by Commissioner Legault, among others, as an important starting point for legislative reform. I have chosen to focus on these two specific recommendations because, in my view, they respond to the most critical threats to our right to access government information.

\section{Duty to record decisions and penalties for destruction of records}

"[The Triceratop's] main predator was the T-Rex. It would protect itself from its predator's large jaw by moving its frill down to protect its bulky body, then attempting to pierce the T-Rex's torso with its two, larger horns."

Recent years have seen a growing trend of government officials, both elected and nonelected, interfering with or evading the right to access government information. The incidents of interference with the right to access information include cases of deleting government emails in Ontario $^{6}$ and British Columbia. ${ }^{7}$ At the federal level, the Tognieri affair provides an example of direct political interference with the right to access government information. A political staffer's instructions to department officials to "unrelease" information that should have been properly disclosed under the Access Act was found to be part of "systemic interference by members of the Minister's Office staff ... during the period investigated." 8

These examples of increasingly active interference with access rights are more disturbing when coupled with the growth of a less aggressive, but no less disturbing, form of attack on access to information: the failure of public officials to keep records of their actions and decisions. At present, there is no positive duty to document decisions taken within the Federal Government. This has allowed government officials to attempt to evade the potential application of the Access Act to their discussions by using means of communication that do not produce permanent records. These tactics, which at one time included the use of "sticky notes" temporarily appended to files that could be removed before disclosure, have now expanded to include the use of text-messaging platforms.

The use of these technologies has become so problematic that the Information Commissioner 
submitted a special report to Parliament dealing with the use of Blackberry PIN to PIN messaging by government officials. In her report, Commissioner Legault documented how the refusal of government departments to store PIN to PIN messages on corporate email servers was allowing these communications to be deleted or effectively shielded from access requests. She concluded that "there is a real risk that information that should be accessible by requesters is being irremediably deleted or lost. No valid operational requirement was provided to me to justify this risk." Another evasive technique observed by the Information Commissioner is the use of exempt (political) staff in Ministers' offices to take notes of meetings between Ministers and other officials. The notes taken by these exempt staff members are then kept in the Minister's office to shield them from disclosure under the Access Act. ${ }^{10}$ Perhaps even more concerning, the Information Commissioner has warned more recently that public officials are increasingly conspiring to hold meetings without taking notes. Described by the Commissioner as "a growing trend of 'LDL' meaning 'Let's Discuss Live,"'11 this trend, has also been described as part of "an emerging oral culture of decision-making." 12

Public officials who actively attempt to frustrate or evade access rights by destroying records or by simply refusing to create the records in the first place are the most aggressive predators faced by our access regime. They are the T-Rex of the current access era and, like the Triceratops, our access regime requires effective 'horns' to defend itself from these predators. To this end, I endorse Commissioner Legault's call for two significant additions to the current federal Access Act. The first addition is the imposition of a comprehensive duty to document the decision-making process of public bodies. Not surprisingly, the imposition of such a duty to document has also been endorsed by all of Canada's Information Commissioners. ${ }^{13}$ The recognition of a duty to document would prohibit officials from using a lack of records to evade disclosure duties. Encapsulating this duty in statutory form would reinforce the importance of maintaining accurate records of government decision-making processes, both for historical purposes and to enhance account- ability. To this end, the duty must also be subject to sanction when it is breached.

\section{Order-making power}

\begin{abstract}
"When dealing with raptors, depending on the size of the raptor, be it Dilophosaurus size or baby Velociraptor size, it was usually much harder for the Triceratops. The Maniraptorans would bite at its legs until it stumbled to the ground in pain. The raptors would then bite and scratch at its body until it passed out so they could eat it."14
\end{abstract}

Just as the Triceratops is slowly drained of life through the bites and scratches of the raptors, so our access rights are brought to their knees through the pernicious impact of widespread delays in the access process. ${ }^{15}$ The Information Commissioner has recommended a number of changes to the Access Act that would make it more difficult for public bodies to delay responding to access requests. These recommendations include restricting the ability of respondents to give themselves lengthy extensions except when demonstrably necessary and requiring permission from the Commissioner for extensions beyond 60 days. ${ }^{16}$

While I support these recommendations, they will be largely ineffectual unless the Access Act is also changed to provide the Commissioner with order-making power. Under the current legislative framework, the Commissioner acts as an ombudsperson who receives complaints concerning the failure of government officials to disclose information. Where the investigations by the Commissioner determine that the information should be disclosed, she can only recommend, not order, that the government actor disclose the information. Similarly, where the Commissioner finds that government departments have improperly delayed the processing of access requests or have given themselves improper extensions on the deadlines for responding to access requests, the Commissioner does not have any effective power to punish or hold the wrongdoer accountable. Rather, the Commissioner is, in many cases, limited to reporting on patterns of excessive delay among government depart- 
ments in the hope of pressuring more efficient processing of access requests.

Providing the Commissioner with ordermaking power would render the Access Act more effective as a mechanism for protecting our right to access government information. The Commissioner has noted that such a shift would, among other benefits, increase certainty by implementing an order after the first stage of review; would motivate institutions to ensure there is sufficient evidence to justify refusals to disclose at the first instance; and would encourage more timely responses due to the power of the Commissioner to order disclosure where unnecessary delays are encountered. ${ }^{17}$ While providing the Commissioner with order-making power may require some changes in the administration of the Access $A c t$, there is little evidence that maintaining the status quo is a desirable way to promote greater or timelier access to information.

\section{B. Executive Evolution: Fostering an Environment that Promotes}

\section{Access}

Legislative amendments will not be sufficient to deal with the chronic problem of delays and the increasing trends of access avoidance; political leadership is required to change the festering culture of delay and avoidance. In a 2010 comparative study of access to information regimes in Australia, New Zealand, Canada, Ireland and the United Kingdom, Robert Hazel and Ben Worthy emphasized the importance of political leadership as a key determinant of the effectiveness of an access to information regime. ${ }^{18}$ The Information Commissioner of Canada has similarly recognized a correlation between the importance accorded to promoting transparency by the leadership within the civil service and the responsiveness of particular departments to access requests. ${ }^{19}$

The importance of strong leadership in promoting transparency is a key reason to welcome the emphasis of the newly elected Liberal Government on promoting greater transparency. Certainly, it is encouraging to see that the Lib- eral Party's promises to increase transparency if elected have been echoed in the mandate letters provided to individual ministers and, most recently, in the federal budget. ${ }^{20}$ Of course, it is important to remember that campaign promises of increased transparency have often faded once candidates win government, even in cases where early actions in government appear promising. The recent decision of the newly elected Liberal Government to release only redacted versions of Canadian reports concerning the human rights record of Saudi Arabia in the face of growing resistance to the deal to sell the kingdom Canadian-made armoured vehicles is but the most recent example of how quickly the tendency to secrecy may infect a newly elected government. ${ }^{21}$

In addition to the important tone-setting by the Prime Minister and other political leaders, there are at least two other ways in which the leadership required to change the political culture to one that embraces greater transparency may be exercised in the administrative realm almost immediately. The first action to improve access to information would be to provide the funding to hire more access coordinators to help reduce the time it takes to process access requests. The Information Commissioner has identified the impact of inadequate resources for processing access requests at the departmental level as a key problem.$^{22}$ In this regard, it is heartening that the 2016 federal budget tabled by the Minister of Finance promises $\$ 12.9$ million over five years for activities related to enhancing access to information, including access to personal information..$^{23}$ However, it remains uncertain how this money will be allocated, and whether it will be used only to enhance access to personal information held by the government.

The second immediate, tangible action would be to adopt administrative guidelines to ensure the preservation of messages sent through text messaging or instant messaging services in order to preserve these records for the purposes of access requests. The Commissioner made these recommendations in her report on instant-messaging practices in the Federal Government, but the Treasury Board has yet to adopt the recommended guidelines. ${ }^{24}$ Implementing 
the guidelines suggested by the Information Commissioner would reflect the government's commitment to ensuring transparency. It would also support the move to legislative renewal by supporting the Commissioner's call for records of text-message communications to be captured under the Access Act.

\section{Judicial Evolution: Protecting Against Cataclysmic Events While Sustaining Existing Rights}

It is hard to deny that the environment in which Western democracies operate has been significantly altered by the rise of foreign and domestic terrorism. Fear of these new threats (both real and perceived) has fostered an acceptance of greater restrictions on liberties and an apparent willingness to trade some liberties and democratic accountability for promises of increased security. However, changes in the existing legislative protections of access rights have not only been introduced as a result of responses to terrorism or other public security concerns. For example, the Federal Government's 2015 omnibus budget bill included provisions that retroactively eliminated the application of the Access Act to existing investigations regarding the potentially unlawful destruction of firearms records by the RCMP. ${ }^{25}$

Shifts in the legislative environment, whether caused by external cataclysmic events such as acts of terrorism or by less abrupt but no less damaging shifts in political culture have the potential to undermine and even extinguish access rights in the same way that cataclysmic events contributed to the eventual extinction of the Triceratops in the Cretaceous period. Thankfully, unlike the Triceratops, access rights in Canada have some protections against such environmental changes, whether gradual or cataclysmic, in the form of judicial enforcement of constitutional norms, robust interpretation of existing legislative rights, and active review of administrative discretion.

\section{Constitutional Interpretation}

The protection of access to information rights in Canada was bolstered by the 2010 decision of the Supreme Court of Canada in Ontario (Public
Safety and Security) v. Criminal Lawyers' Association. ${ }^{26}$ For the first time, the Supreme Court of Canada explicitly recognized a constitutional foundation for protecting access to information rights. In particular, the Court found that section 2(b) of the Charter protects a derivative right to access government information. ${ }^{27}$

In the decision, Chief Justice McLachlin and Justice Abella, writing for the Court, developed a modified Irwin Toy test to determine whether the derivative right to access government information, protected by section 2(b), is infringed upon in a particular case. Unfortunately, the test adopted by the Court has significant restrictions that may render it difficult to trigger the protection of access rights under section 2(b). ${ }^{28}$ These restrictions may be categorized as follows: a right to access is only protected where (a) the access is a necessary precondition to meaningful expression; (b) access does not encroach on protected privileges; and (c) access is not incompatible with the function of the institution concerned. ${ }^{29}$

Notwithstanding these significant limitations, the Criminal Lawyers' Association decision marks an important progression in the protection of access to government information rights in Canada as it provides an important recognition that constitutional protection is available. As such, there are now constitutional limitations to the extent to which legislatures and government actors can restrict our right to access government information. While most of the existing statutory limitations on access will likely pass constitutional review, it is possible that new, more severe restrictions on access may be successfully challenged as unconstitutional. Thus, for instance, one can argue that the retroactive elimination of a right to access information concerning the federal long-gun registry imposed through the 2015 omnibus budget bill was a restriction on information necessary to allow for meaningful commentary concerning the registry. Similarly, attempts to eliminate existing access rights may now be subject to constitutional scrutiny. In this way, the newly recognized derivate right of access to government information included under section 2(b) of the Charter may serve, if more fully developed in future cases, as a protective 'dome' 
against cataclysmic changes to the access environment faced by our Triceratops.

\section{Legislative Interpretation}

The courts also have a role to play in protecting our rights to access legislation through the process of statutory interpretation. By ensuring a purposeful interpretation of access legislation, courts can ensure that existing legislative frameworks provide the best possible protection of access.

The core approach to interpreting access to information legislation in Canada generally recognizes the following elements:

a) that the right of access to government information is a key requirement to promote public participation in the political process and to ensure accountability of government officials;

b) that the right to access should receive a large and liberal interpretation that considers the above-noted purpose of access;

c) that restrictions on the right to access should be interpreted strictly and narrowly; and,

d) that there should be an independent review of decisions concerning access.

Unfortunately, the Supreme Court's approach to interpretation of access to information legislation has been uneven in recent cases, as can be demonstrated through a comparison of the majority decisions in two recent cases: the Prime Minister's Agendas case ${ }^{30}$ and Merck Frosst Canada Ltd $v$ Canada (Health). ${ }^{31}$

One of the main issues to be decided by the Supreme Court in the Prime Minister's Agenda case was whether the PMO or Ministers' Offices are government institutions under the Access Act. Justice Charron, writing for the majority, concluded that neither the PMO nor Ministers' offices could be considered government institutions subject to the Access Act. She further held that the records at issue were not "under the control" of a government institution in the case. Two aspects of the interpretive approach adopted by Justice Charron raise alarm bells. A primary concern is that Justice Charron's reasons emphasized the importance of exceptions to disclosure as opposed to the imperative of disclosure. As noted above, the accepted approach to interpreting access to information legislation - an approach that is statutorily mandated in the Access Act - is that the legislation be interpreted broadly and that necessary exceptions be construed narrowly. ${ }^{32}$ This approach is based on the principle that those few exceptions that are proven to be necessary should be narrowly construed in order to fulfill the democracy-enhancing roles of access to information legislation.

In her decision, Justice Charron seems to have reversed the interpretation of section 2 of the Access Act in order to emphasize the fact that the exceptions to disclosure that are identified in the Act are necessary. In her words, “... the statute expressly recognizes that information in the hands of government institutions 'should be available to the public,' but the right to access it is subject to 'necessary exceptions."' 33 Justice Charron later reemphasized the importance of the exceptions, noting: "It is important to recall that Parliament's statement of purpose in [section] 2 of the Act recognizes that exceptions to public accessibility are "necessary." 34 She went on to describe the rationale behind a number of exemptions from disclosure that are included in the Access Act. However, Justice Charron failed to note that the clause in section 2 of the Access Act that includes the term "necessary exceptions" states that "necessary exceptions to the right of access should be limited and specific." As a result, Justice Charron appears to have used the "necessity" of the "exception to the right of access" as a justification for broadly interpreting the scope of the exception instead of abiding by the legislatively mandated approach of ensuring that any exceptions are "limited and specific."

The lasting impact of Justice Charron's conclusion that Ministers' offices are not to be included in the definition of government institution in the Act remains uncertain in light of amendments promised by the new Liberal Gov- 
ernment to bring Ministers under the scope of the Act. However, I remain concerned that Justice Charron's emphasis on the necessity of the exceptions may lead to an expansive interpretation of the exceptions to the right to access in future cases.

In contrast to the approach to statutory interpretation adopted in the Prime Minister's Agenda, the majority decision of Justice Cromwell in the Merck Frosst case reflects a more traditional application of the purposive approach to interpreting access legislation, emphasizing that restrictions on access should be narrowly construed in light of the democracy-enhancing purposes of the legislation. The dispute in this case focused on the proper interpretation of sections 20, 27, and 28 of the Access Act. Section 20 establishes exemptions from disclosure for information that contains trade secrets of third parties, particular types of confidential information provided to a government institution by a third party, or information that could reasonably be expected to affect the financial or competitive position of a third party. Sections 27 and 28 outline the procedure for advising a third party if a government institution intends to disclose the third party's information. ${ }^{35}$ Under the Access Act, a third party that believes a government institution is going to improperly disclose its protected information can challenge the decision of the institution to release the information. ${ }^{36}$ Merck Frosst sought a broad definition of the information protected from disclosure under section 20 in order to protect against disclosure of information it believed should be kept secret.

The majority of the Court rejected Merck Frosst's claims for a broader interpretation of the exceptions to disclosure in the case. Justice Cromwell's interpretation of these sections of the Access Act in Merck Frosst constantly engaged with the purposes of the Act and explicitly acknowledged the edict that limitations to the right to access should be limited and specific. His purposive approach was most apparent when he reviewed the meaning of section 20 of the Act. First, in interpreting the term "trade secrets" in section 20(1), Justice Cromwell conducted an extensive review of the technical meaning of the term, the understanding of the term in both the civil and common law, the framework provided by the Act as a whole, and leading decisions interpreting the term. Ultimately, Justice Cromwell opted for a narrower definition of "trade secrets" than argued for by Merck Frosst, noting that a narrower, more technical definition reflected the "principle that exceptions to the right of access should be limited and specific (s.2(1)). In this way, the Act's purpose of providing broad access rights is protected." ${ }^{37}$

Justice Cromwell's analysis of the exceptions to disclosure under the federal Access Act is an excellent example of the purposive approach to interpreting access legislation - one that acknowledges that the democracy-enhancing purpose of access legislation can only be achieved by ensuring that exceptions to disclosure are strictly interpreted in order to ensure that they are limited and specific. The Court's endorsement of this approach in the Merck Frosst case helps to alleviate some of the concerns raised by the less purposive analytical approach adopted in the PM's Agenda case. However, it is also important to recognize that the exceptions at issue in the Merck Frosst case operated to the benefit of third parties, not government actors. Thus, while government officials are responsible for implementing the trade-secret exemptions, the exemptions do not operate to insulate government information from disclosure. As a result, the Court's less deferential approach in interpreting the scope of the exceptions to disclosure in Merck Frosst may be explained, at least in part, by the fact that its interpretation did not have to consider the impact of access on the function of government. In order to ensure the robust protection of access to information rights, courts must apply a purposive approach to interpreting existing legislative provisions, one that ensures that limitations on the right to access are limited and specific, regardless of whether the limitations apply to government institutions or third parties.

\section{Supervision of Administrative Action}

Finally, it is worth considering the important role that courts play in preserving an environment that facilitates access to government information through their role in supervising administrative 
action. This role is particularly important in light of the wide scope of discretion that is accorded to public officials under many of the exemptions to disclosure obligations included in access to information legislation. The Supreme Court of Canada's decision in the Criminal Lawyers' Association case highlights the expectation that public officials who exercise a discretion not to disclose information pursuant to an exemption in access to information legislation must always weigh the public interest in disclosing the information in addition to the reasons for refusing to disclose the information. ${ }^{38}$

Most recently, in Ontario (Community Safety and Correctional Services) v Ontario (Information and Privacy Commissioner), the Supreme Court of Canada also confirmed that public officials must provide sufficient evidence of harm before they can rely upon a harm-based exemption to justify a refusal to disclose information under access legislation. ${ }^{39}$ This case is part of a trend of judicial decisions articulating the expectation that officials must provide evidence that supports their reliance on statutory exemptions to disclosure, including findings by the Federal Court of Appeal in Attaran v Canada (Minister of Foreign Affairs $)^{40}$ in addition to statements clarifying the conditions for relying upon statutory exemptions in the Supreme Court's decisions in the Criminal Lawyers Association and Merck Frosst decisions discussed above. ${ }^{41}$

Continued active review of official decisions to refuse disclosure is essential for the robust protection of access rights. Review ensures that public officials cannot simply claim that they have good reasons for relying on mandatory exemptions from disclosure or for exercising their discretion to refuse to disclose information that might otherwise be disclosed. Requiring officials to provide evidence to support their decisions to refuse disclosure allows those decisions to be more effectively vetted, and is thereby likely to promote a more meaningful consideration of the public interest.

\section{Conclusion}

The election of a new government promising important reforms to our democratic institutions, including changes to electoral laws, Senate appointments, and improvements to our access to information regime marks a potential for renewed democracy in Canada. Are we, in fact, witnessing the dawn of a new age in Canadian democracy, an age of increased transparency and accountability, an age where participation is fostered rather than inhibited? Or, will our democratic institutions continue to stagger toward oblivion, failing, like the once-mighty Triceratops, to adapt to the threats posed by more voracious predators, a changing (technological and political) environment, and the fallout from cataclysmic events like terrorist attacks? Where the right to access government information is concerned, the answer to these questions will be determined by the combined responses of the legislature, executive, and judiciary.

Our access rights will continue to weaken unless the legislature implements important changes to our federal Access Act. At the same time, the negative climate fostered by a political and administrative culture of delay and avoidance will only be successfully combatted if an explicit and forceful commitment to transparency is manifested by political and civil service leaders. Finally, our rights to access information require continued protection from the judiciary. To this end, the survival of our right to access will be fostered by the application of the newly recognized constitutional protection of access, through a renewed emphasis on purposive interpretation of existing statutory access rights, and through ongoing robust review of administrative decisions that limit disclosure of government information. In this way, the judiciary can help protect our existing rights to access from the most damaging effects of long-term changes in the political environment while we await the legislative and executive action necessary to create a more evolved, modern, and resilient federal access to information regime. This modern access regime, together with the modernization of other important democratic institutions and 
processes, will help foster a new, more vibrant, age of Canadian democracy.

\section{Endnotes}

* Vincent Kazmierski is an Associate Professor in the Department of Law and Legal Studies at Carleton University.

1 Bob Straus, "10 Facts About Triceratops," About. com (June 2, 2016), online: <http://dinosaurs. about.com/od/typesofdinosaurs/ss/10-FactsAbout-Triceratops.htm\#step11>.

2 Access to Information Act, RSC 1985, cA-1 [Access Act $]$.

3 Commissioner Reid tabled a new draft act in 2005, see: Information Commissioner of Canada, Proposed Changes to the Access to Information Act: Presentation to the Committee on Access to Information, Privacy and Ethics (Ottawa: Information Commissioner of Canada, 2005). Next, Commissioner Marleau tabled his own recommendations for improvements to the Access Act in 2009, see: Information Commissioner of Canada, Strengthening the Access to Information Act to Meet Today's Imperatives (March 4, 2009), online: Information Commissioner of Canada <http:// www.oic-ci.gc.ca/eng/pa-ap-atia_reform_2009march_2009-strengthening_the_access_to_ information_act_to_meet_todays_imperatives. aspx $>$. For a brief discussion of suggestions for reforms to the Access Act between 2005 and 2010, see: Vincent Kazmierski, "Accessing Democracy: The Critical Relationship between Academics and the Access to Information Act" (2011) 26:3 CJLS 613 at $618-621$.

4 Information Commissioner of Canada, Striking the Right Balance for Transparency: Recommendations to Modernize the Access to Information Act (Minister of Public Works and Government Services, 2015), online: Information Commissioner of Canada <http://www.oic-ci.gc.ca/eng/rapportde-modernisation-modernization-report.aspx $>$ [Striking the Right Balance].

5 "Predators," Triceratops Facts!, online: <http:// facts-triceratops.weebly.com/predators.html>.

$6 \mathrm{CBC}$ News "Ontario Liberals paid $\$ 10,000$ to have gas plant data erased: OPP", Canadian Broadcasting Corporation (18 December 2014), online: <http://www.cbc.ca/news/canada/toronto/ ontario-liberals-paid-10-000-to-have-gas-plantdata-erased-opp-1.2877944>.

7 Information and Privacy Commissioner of British Columbia, Investigation Report F15-03, Access Denied: Record Retention and Disposal Practices of the Government of British Columbia 2015 BCIPC No. 63 (CanLII).

8 Information Commissioner of Canada, Interference with Access to Information, Part 2 (April 2014), online: Information Commissioner of Canada $<$ http://www.oic-ci.gc.ca/eng/ingerence-dansacces-a-l'information-partie-2-interferencewith-access-to-information-part-2.aspx $>$ at 16 [emphasis added].

9 Information Commissioner of Canada, Access to Information at Risk from Instant Messaging (November 2013), online: Information Commissioner of Canada <http://www.oic-ci. gc.ca/eng/pin-to-pin-nip-a-nip.aspx\#2> at 3 [Risk from Instant Messaging].

10 Striking the Right Balance, supra note 4 at 10.

11 Information Commissioner of Canada, "2016: The Year of Access to Information?" (Speaking Notes for the Commissioner at the CAPA Conference, November 30, 2015), online: Information Commissioner of Canada<http://www.oic-ci. gc.ca/eng/media-room-salle-media_speechesdiscours_2015_6.aspx $>$.

12 Information Commissioner of Canada "Information Commissioners call on governments to create a duty to document," online: Information Commissioner of Canada <http://www.oicci.gc.ca/eng/communique-de-presse-newsreleases-2016_3.aspx?pedisable $=$ true $>$.

13 Ibid.

14 “Triceratops Facts!" supra note 5.

15 In a 2010 report on the issue of delay, the Information Commissioner noted: "This right is at risk of being totally obliterated because delays threaten to render the entire access regime irrelevant in our current information economy." Information Commissioner of Canada, 20082009 Report Cards - Out of Time: Systemic Issues Affecting Access to Information in Canada, online: Information Commissioner of Canada <http:// www.oic-ci.gc.ca/eng/rp-pr_spe-rep_rap-spe_ rep-car_fic-ren_2008-2009.aspx> at 2 [Out of Time].

16 Ibid at 29.

17 Ibid at 71-72.

18 They noted: "Above all, an effective FOI regime requires strong government commitment and political will. Officials cannot do it on their own. Given strong political support, it is much easier 
to put other supportive factors in place..." Robert Hazell \& Ben Worthy, "Assessing the performance of freedom of information" (2010) Government Information Quarterly 352 at 358.

19 Out of Time, supra note 15 at 2.

20 See, for example, the "Minister of Health Mandate Letter," online: Government of Canada, <http:// pm.gc.ca/eng/minister-health-mandate-letter>. See also: "Chapter 7 - Open and Transparent Government" in Government of Canada, Budget, 2016, online: Government of Canada <http:// www.budget.gc.ca/2016/docs/plan/ch7-en.html> [Budget, 2016].

21 Daniel Leblanc \& Steven Chase, "Ottawa to Release Redacted Version of Saudi Human-Rights Study" The Globe and Mail (10 January 2016), online: <http://www.theglobeandmail.com/news/ politics/ottawa-to-release-redacted-version-ofsaudi-human-rights-study/article28102622/>.

22 Out of Time, supra note 15 at 15.

23 Budget 2016, supra note 20.

24 Risk from Instant Messaging, supra note 9.

25 Bruce Cheadle, "Omnibus Budget Bill Rewrites History To Clear RCMP of Potential Criminal Charges" The Globe and Mail (13 May 2015), online: <http://www.theglobeandmail.com/news/ politics/omnibus-budget-bill-alters-historyto-clear-rcmp-of-potential-criminal-charges/ article24417074/>. The legislative provisions were passed: Economic Action Plan 2015 Act, No. 1, SC 2015, c36, ss. 230-231.

26 Ontario (Public Safety and Security) v Criminal Lawyers' Association, 2010 SCC 23, [2010] 1 SCR 815 [Criminal Lawyers' Association].

27 Ibid at para 30.

28 The scope of this paper requires that a fuller discussion of these limitations will have to await another article.
29 Criminal Lawyers' Association, supra note 26 at para 5.

30 Canada (Information Commissioner) v Canada (Minister of National Defence), 2011 SCC 25, [2011] 2 SCR 306 [Prime Minister's Agenda].

31 Merck Frosst Canada Ltd v Canada (Health), 2012 SCC 3, [2012] 1 SCR 23 [Merck Frosst].

32 Section 2(1) of the Access Act states:

2. (1) The purpose of this Act is to extend the present laws of Canada to provide a right of access to information in records under the control of a government institution in accordance with the principles that government information should be available to the public, that necessary exceptions to the right of access should be limited and specific and that decisions on the disclosure of government information should be reviewed independently of government.

Access Act, supra note 2, s 2(1).

33 Prime Minister's Agenda, supra note 30 at para 16 [emphasis in original].

34 Ibid at para 41.

35 Access Act, supra note 2, ss 20, 27, 28.

36 Ibid, s 44.

37 Merck Frosst, supra note 31 at para 106.

38 Vincent Kazmierski, "Lights, Judges, Access: How Active Judicial Review of Discretionary Decisions Protects Access to Government Information" (2013) 51:1 Alta L Rev 49.

39 Ontario (Community Safety and Correctional Services) $v$ Ontario (Information and Privacy Commissioner), 2014 SCC 31, [2014] 1 SCR 674.

40 Attaran $v$ Canada (Minister of Foreign Affairs), 2011 FCA 182, 420 NR 315, leave to appeal refused, 34402 (29 March 2012), 434 NR 392 [Attaran].

41 Merck Frosst, supra note 31, paras 192-227. 